\title{
Effect education based on trans-theoretical model on reduction of the prevalence of gingivitis among pregnant women: Application of Telegram social network
}

\author{
Rahmani $A^{1}$, Allahqoli L ${ }^{2}$, Hashemian $\mathbf{M}^{3}$, Ghanei Gheshlagh $\mathbf{R}^{4}$, Nemat-Shahrbabaki $\mathbf{B}^{5}$ \\ 1. Assistant of Professor, Nursing and Midwifery Care Research Center, School of Nursing and Midwifery, Tehran \\ University of Medical Sciences, Tehran, Iran. \\ 2. Assistant of Professor, Endometriosis Research Center, Iran University of Medical of Sciences (IUMS), Tehran, Iran. \\ 3. Assistant of Professor, Department of Health Education, Sabzevar University of Medical Sciences, Sabzevar, Iran. \\ 4. Assistant of Professor, Department of Nursing, Faculty of Nursing and Midwifery, Kurdistan University of Medical \\ Sciences, Sanandaj, Iran. \\ 5. Msc of Health Service Management, Health Network of Sanandaj, Kurdistan University of Medical Sciences, Sanandaj, \\ Iran (Corresponding Author), Tel: +989132405863, Email: babak.nemat@yahoo.com
}

\begin{abstract}
Background and Aim: Gingivitis has high prevalence among pregnant women and educational programs have resulted in little success in the improvement of this disorder. The aim of this study was to determine the effect of trans-theoretical model based education on reduction of the prevalence of gingivitis among pregnant women through Telegram social network.

Materials and Methods: This experimental study was conducted in Sanandaj City, in the west of Iran in 2018. 160 pregnant women were assigned to intervention and control groups. The participants completed a two-part questionnaire, including demographic variables and trans-theoretical model constructs before and after intervention. The interventional program was delivered through Telegram, and its effect on decreasing gingivitis was evaluated after 24 weeks. The gingival indices were recorded before and after intervention. Data were entered into SPSS-21 software and analyzed by chi-square, independent t-test and one-way ANOVA.

Results: After the intervention, $67.5 \%$ of pregnant women in the intervention group (versus $16.6 \%$ in control group) performed the dental cleaning behavior $(\mathrm{p}<0.01)$. Moreover, there was a significant difference between the intervention and control groups in the mean scores of perceived benefits and gingival indices after the intervention $(p<0.01)$.

Conclusion: Oral health education in the patients with gingivitis could have a significant effect on decreased rate of gingival indices. Telegram social network as an electronic educational tool could be useful for this education and potentially improves the status of the patients with oral diseases.
\end{abstract}

Keywords: Pregnant women, Gingivitis, Education, Social network

Received: Mar 16, 2019 Accepted: April 20, 2019

How to cite the article: Rahmani A, Allahqoli L, Hashemian M, Ghanei Gheshlagh R, Nemat-Shahrbabaki B. Effect of trans-theoretical model based education on reduction of the prevalence of gingivitis among pregnant women: Application of Telegram social network. SJKU 2019;24(2):74-83. 


\title{
تأثير آموزش مبتنى بر التكوى فرا نظريهاى بر كاهش التهاب لثه زنان باردار: كاربرد شبكه اجتماعى تلكرام
}

\author{
اعظم رحمانى'، ليلا الشقلى"، معصومه هاشميان"، رضا قانعى قشلاق"، بابك نعمت شهر بابكىه \\ ا.ـاستاديار، مركز تحقيقات مراقب بِرستارى و مامايى، دانشكده يُرستارى و مامايى، دانشكاه علوم يز شكى تهران، تهران، ايران.

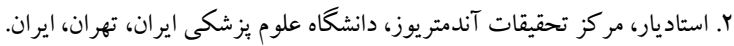

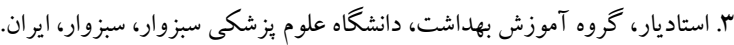

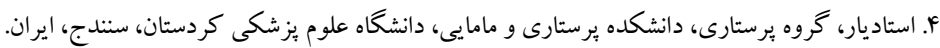

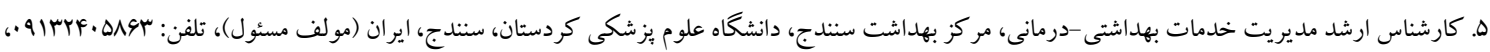

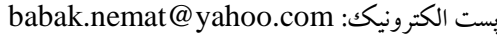

جكيده

زمينه و هدف: التهاب لثه در زنان باردار شيوع بالايى داشته و برنامههاى آموزشى بهبود كمى در آن حاصل كردهاند. هدف از

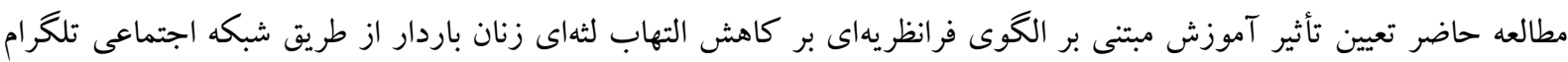

روش بررسى: اين مطالعه تجربى در سال Vوسا در شهر سندج در غرب ايران انجام گرفت. •19 زن باردار در دو گروه آزمون و

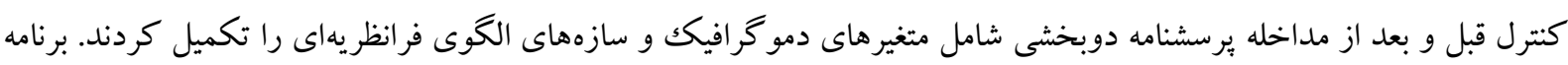

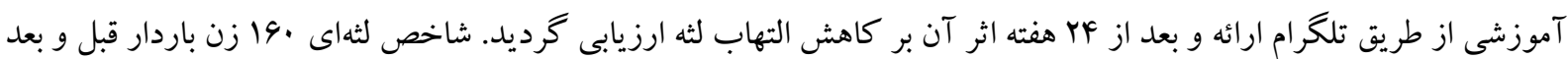

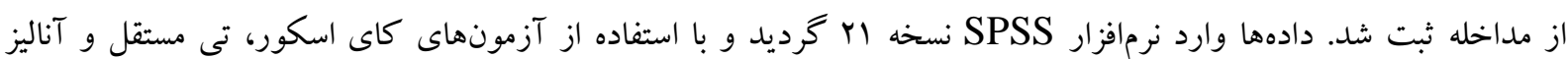
واريانس يكك طرفه آناليز شد.

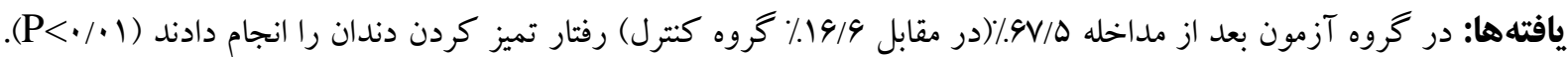

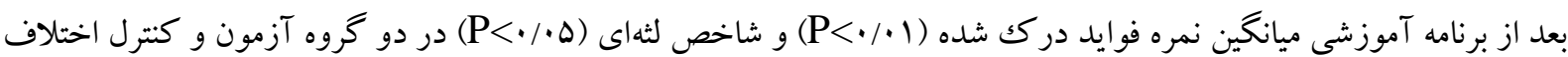

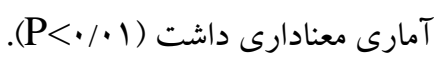
نتيجه كيرى: آموزش مرتبط به سلامت دهان در بيماران مبتلا به التهاب لثه مىتواند در كاهش شاخص لثهاى مؤثر باشد. شبكه

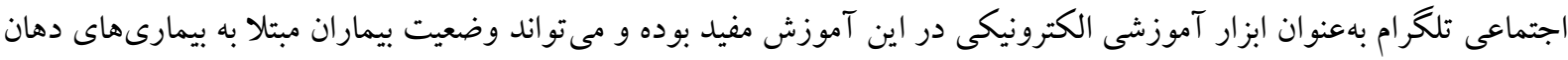

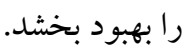

كليد وازه ها: زنان باردار، التهاب لثه، آموزش، شبكه اجتماعى بهد

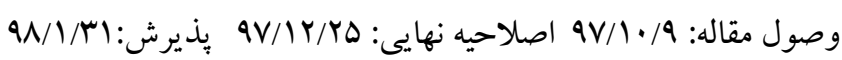


باردار از طريق شبكهى اجتماعى تلخُرام بررسى نكردهاند

مقدمه

$(11,1 \%)$

شبكه اجتماعى تلكُرام كاربران بسيارى را به خود اختصاص

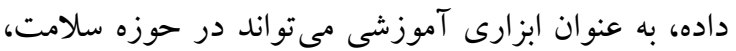
ارتباطات، حمايت اجتماعى و دريافت اطلاعات مفيد باشد(f) أشبكهاى اجتماعى به مكانى براى آموزش تبديل

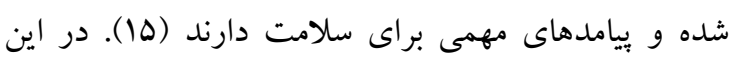

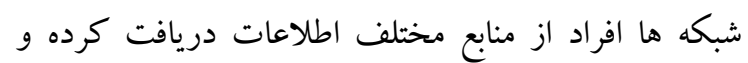

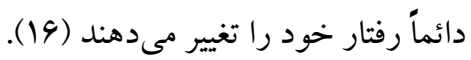

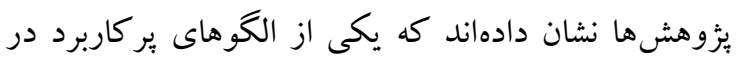

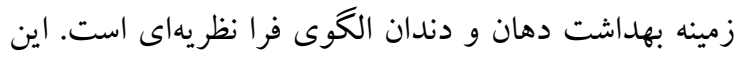
مدل توسط يروجاسكا و ديكلمنت طراحى و شامل جهار

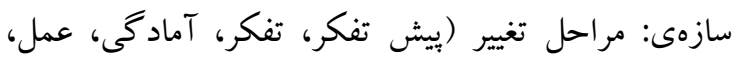

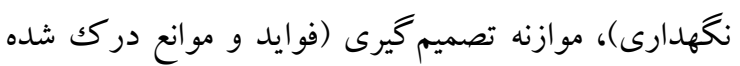

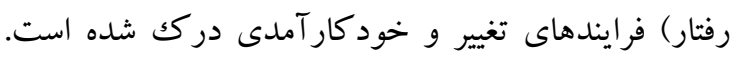
مستندات موجود تأثير برنامهاى آموزشى طراحى شئ شده

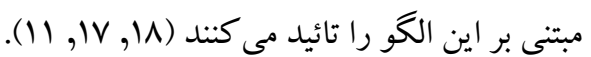
با توجه به اهميت سلامت دهان و دندان در سلامت بدن (11)، نقش آن در سلامت روانى و اجتماعى (19)، نقش مهم مادران در سلامت دهان و دندان خانواده (·Y)، بىتوجهى زنان باردار به بيمارىهاى دهان و دندان (11)، اثر گذارى ناكافى برنامههاى آموزش بهداشت دهان و دندان در مادران (·()، رضايت بايين از وضعيت سلامت دهان و بران

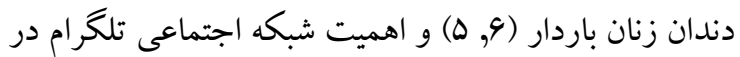
حوزه سلامت (If) بر لزوم انجام مطالعه حاضر با هدف

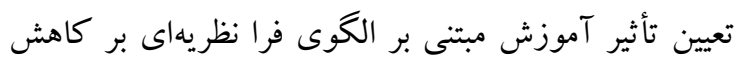

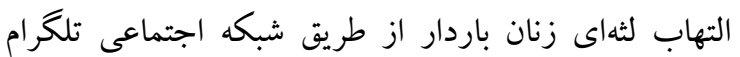

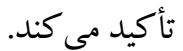

بهداشت دهان و دندان از شاخصهاى مهم در بهداشت عمومى است كه در دوران باردارى اهميت بيشترى بيدا مى كند (1). تغييرات هورمونى دوران باردارى زمينه را براى بيمارىهاى لثه فراهم كرده و اين بر لزوم مراقبت بيشتر از

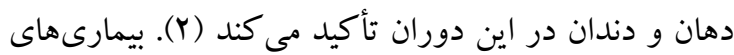
يريودنتال طى دوران باردارى با بِيامدهاى نامطلوبى مانند

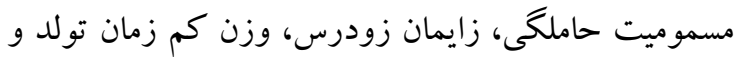
افزايش زمان بسترى نوزاد در ارتباط مىباشند (؟F, r). علىرغم اهميت بهداشت دهان و دندان در طول دوران بـان

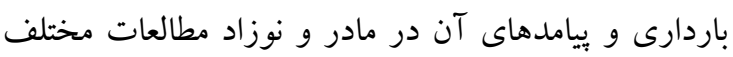
نشان دادهاند كه وضعيت بهداشت دهان در دوران باردارى باري

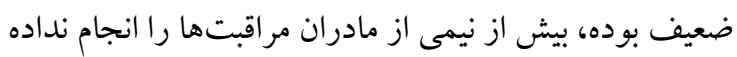

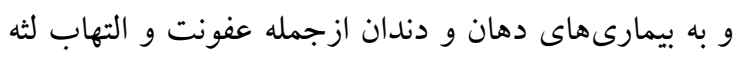

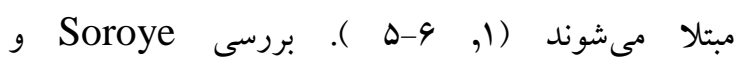
Ayanbadejo

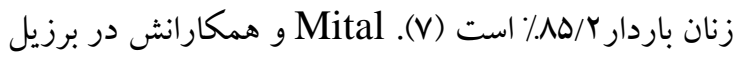

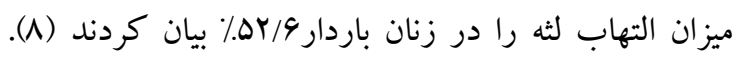
Saddki به بيمارىهاى دهان و دندان بىتوجه بوده و وضعيت دندانها يشان را خوب ارزيابى مى كنند (9). در ايران نيز مطالعات نشان مىدهند وضعيت سلامت دهان اكثريت زنان بهويزه زنان باردار رضايتبخش نبوده (•(1)،

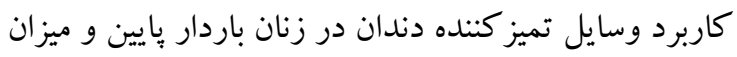

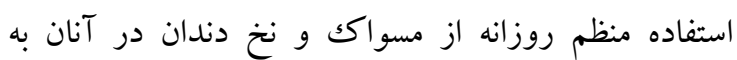

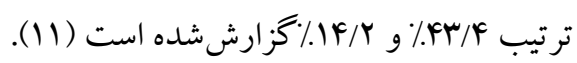
مطالعات بر ارائه آموزشهاى مراقبت از دهان در زنان باردار جهت انجام رفتارهاى سلامت دهان و دندان أنسأ مأكيددارند (Y) سلامت دهان و دندان را بر كاهش التهاب لثهاى در زنان 


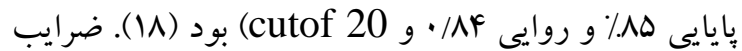

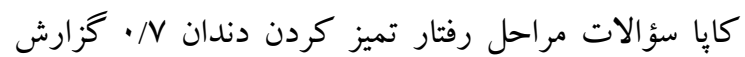

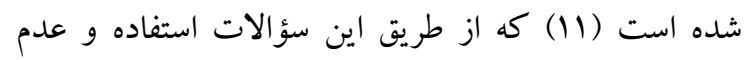
استفاده از وسايل تميز كننده دندان مشخص شد. پِّ از از جمع آورى يرسشنامهها اطلاعات وارد نرم افزار آمارى

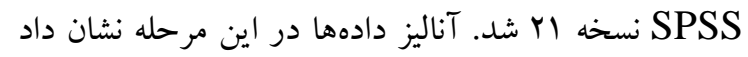

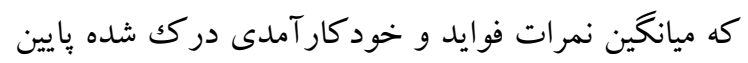

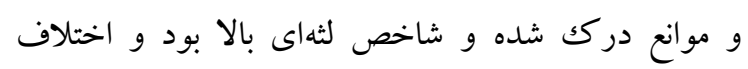
آمارى معنادارى بين دو گروه در اين مرحله مشاهده نشد.

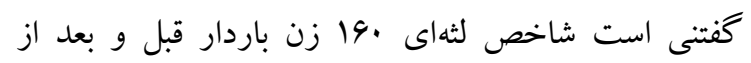
مداخله توسط دندانيزشك در اتاقى داراى نور و امكانات مناسب ثبت شد. اين شاخص داراى سه درجه است (درجه ا:

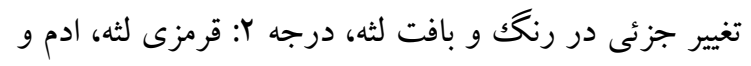

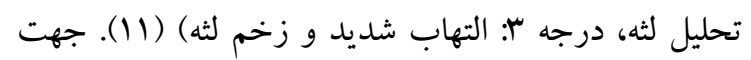

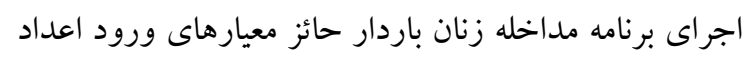

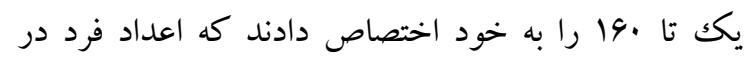
گروه آزمون و اعداد زوج در گروه غير آزمون قرار گرفتند. به صورت تصادفى ساده به دو گروه آزمون و غير آزمون(هر كرو أزمون

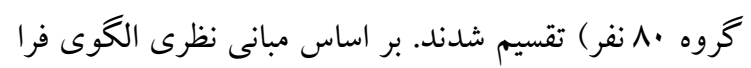

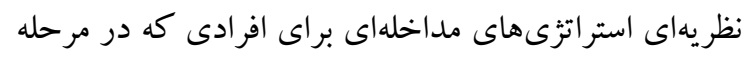
بيش تفكر رفتار تميز كردن دندان قرار دارند شامل افزايش

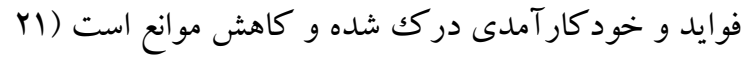

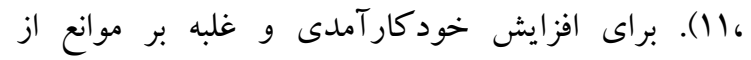

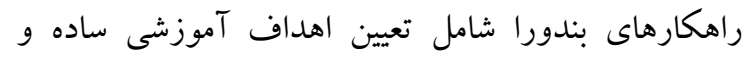
مشخص، تشويق در انجام عملكردهاى مشخص و بيان تجرييات موفق استفاده گرديد (Yr). جهت افزايش فوايد درك شده، مزاياى استفاده از وسايل تميز كننده دندان

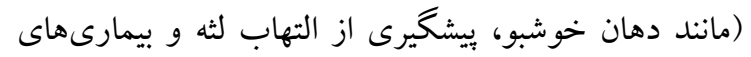
قلبى-عروقى و ...) از طريق كانال تلكرام آموزش داده شد. Bass Method مسواكك زدن (سץ)، استفاده صحيح از نخ دندان و خلال دندان نيز از طريق ارسال جند كليب آموزش داده

\section{روش بروسى}

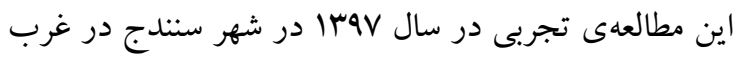
ايران انجام شد. با استفاده از فرمول حجم نمونه

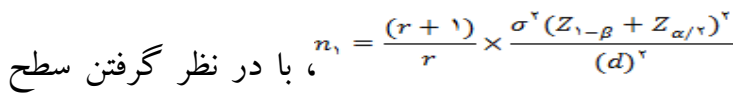

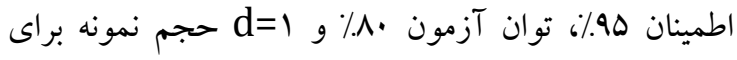

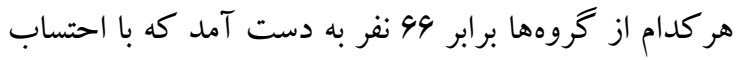

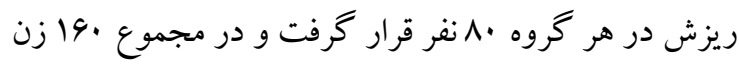

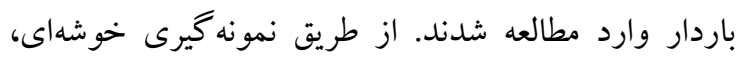
شهر سنتدج به سه خوشه تقسيم شد كه هر خوشه شامل 9 پايگاه خدمات جامع سلامت بود. از هر خوشه تعداد هـ مركز بهور تصادفى ساده انتخاب و .19 زن باردار به شيوه تصادفى ساده وارد مطالعه شدند. معيارهاى ورود شامل زنان

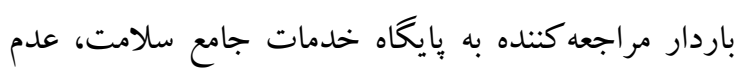

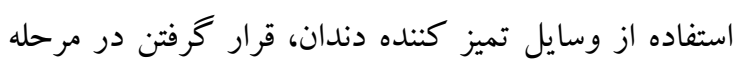

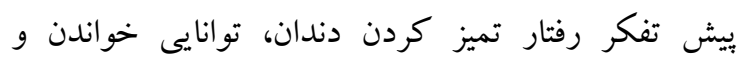
نوشتن، تمايل جهت شركت در مطالعه و داشتن كانال

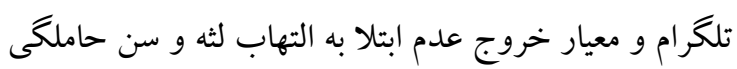

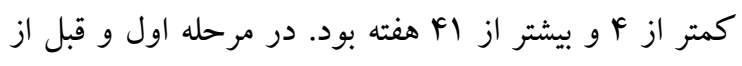

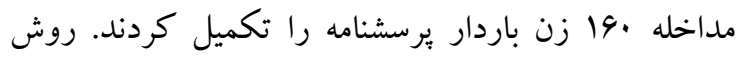
جمع آورى دادهها با استفاده از برسشنامهاى دوبخشى بوده. بخش اول شامل اطلاعات زمينهاى (تعداد افراد خانواده، شغل، شغل همسر، در آمد، تحصيلات، ارزيابى سلامت دهان و فراوانى مراجعه به دندانيزشك) و بخش دوم سازههاى

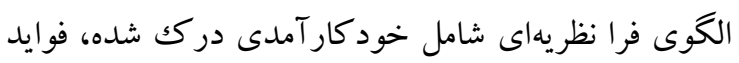
و موانع دركك شده و مراحل تغيير رفتار (شامل ينج مرحله

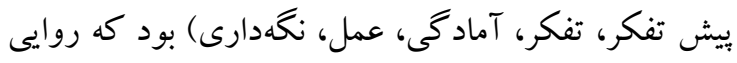

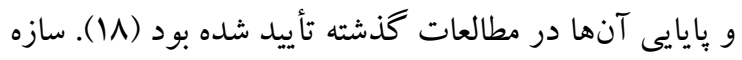

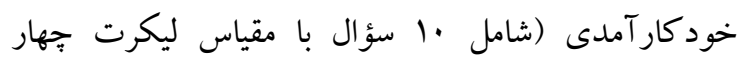

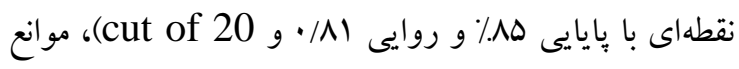

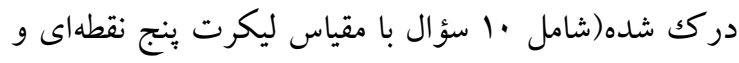

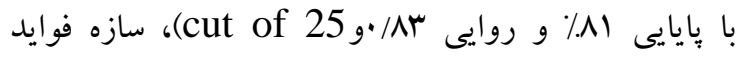

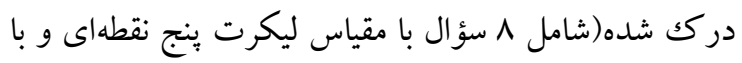


تاثير آدوزش هبتنى بر... VA

گروه آزمون و كنترل را نشان مىدهد. دو گروه از لحاظ ويزگىهاى دموگر افيك تفاوت آمارى معنادارى نداشتند. بيش از نيمى از زنان باردار ارزيابى خوبى از وضعيت سلامت دندانهايشان داشته و تقريباً •هـ٪ آنان معاينات سالانه

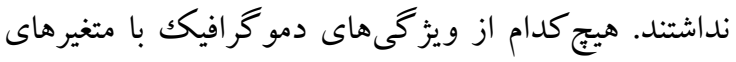

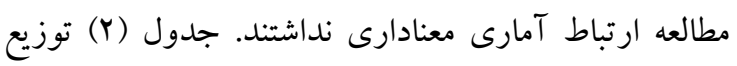

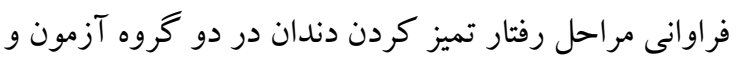

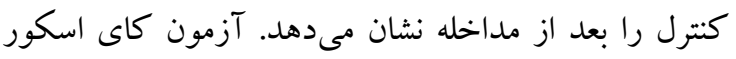

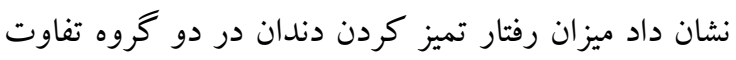

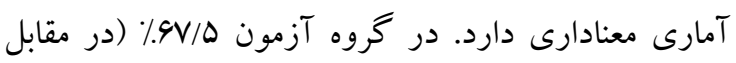

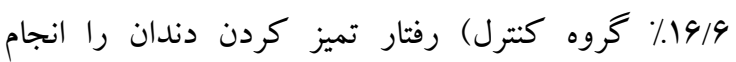

$$
\text { مى دادند (P<./ (P<). }
$$

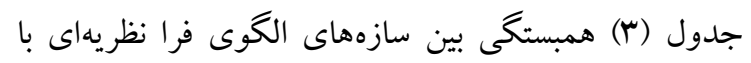

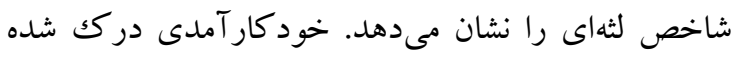
با موانع درك شده و شاخص لثهاى ارتباط آمارى معنادار

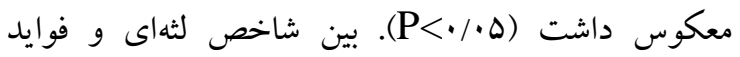
در كك شده ارتباط آمارى معنادارى مشاهده نشد.

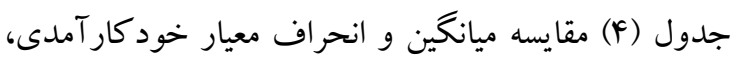

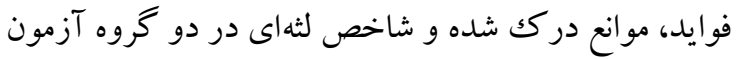

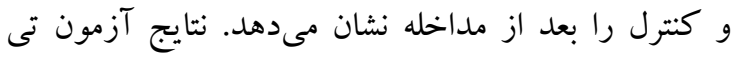

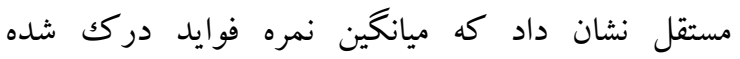

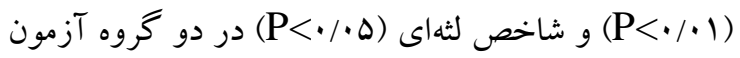

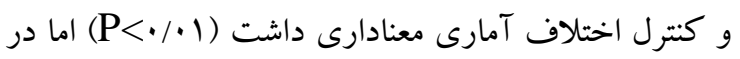

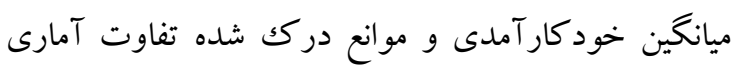

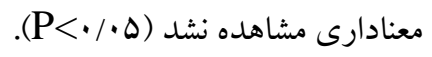

شد.مداخله به مدت r هفته مداوم و سه بار در هفته انجام

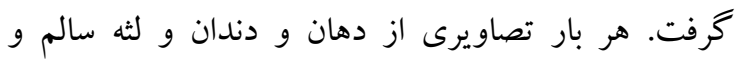

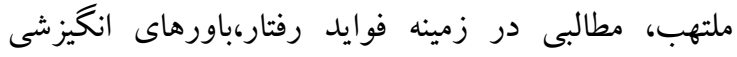

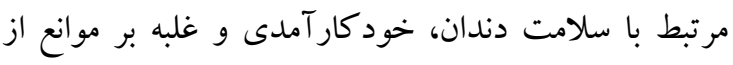

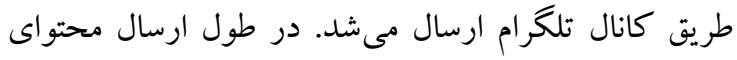

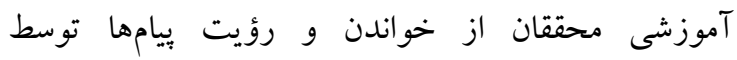

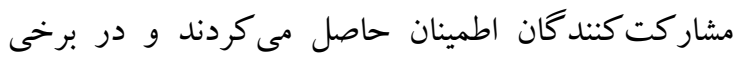

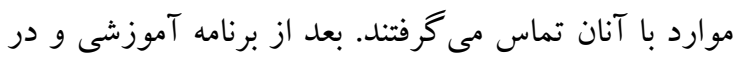
هفتهاى 1 و 19 خلاصهاى از برنامههاى آموزشى مجدداً

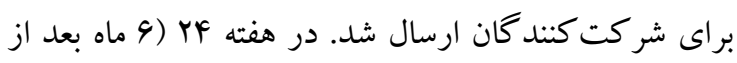

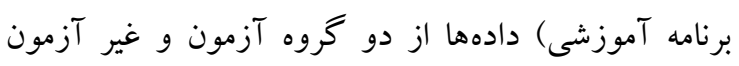

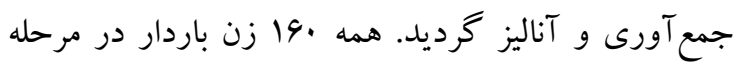
بعد از آزمون حضور داشتند. گفتنى است گروه غير آزمون

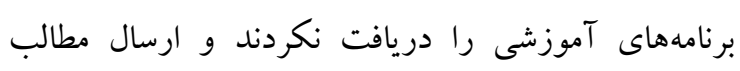

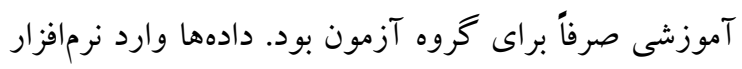

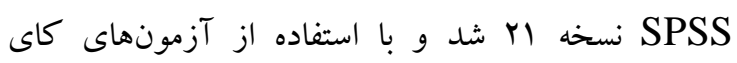

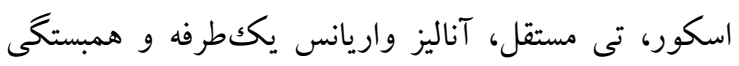
آناليز گرديد.

به منظور رعايت ملاحظات اخلاقى، اهداف و روش يزوهش براى مسئولين و زنان باردار توضيح داده شد و فرم رضايت

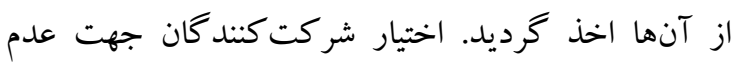

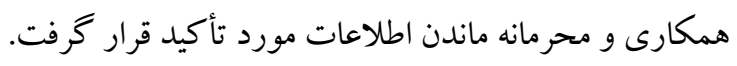

\section{يافتهها}

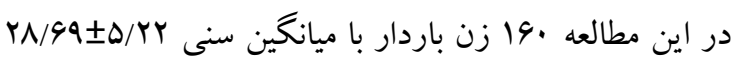

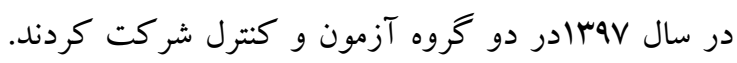

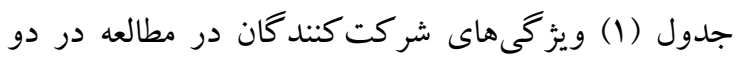


جدول ا: ويز گیىهاى زنان مورد مطالعه

\begin{tabular}{|c|c|c|c|c|c|c|c|}
\hline \multirow{2}{*}{$\chi^{2}$} & \multirow{2}{*}{$\begin{array}{l}\text { P-Value } \\
\left(\chi^{2} \text { test }\right)\end{array}$} & \multicolumn{2}{|c|}{ كنترل } & \multicolumn{2}{|c|}{ مداخله } & & \multirow{2}{*}{ متغيرهاى دمو گر افيكى } \\
\hline & & درصد & فراوانى & درصد & فراوانى & & \\
\hline \multirow{2}{*}{$r / \Delta F$} & \multirow{2}{*}{$\cdot / \cdot 1$} & $11 / r$ & 9 & $r \cdot / \Delta$ & 19 & $1-r$ & \multirow{2}{*}{ تعداد اعضاى خانواده } \\
\hline & & $M / \Lambda$ & vi & $\vee 9 / \Delta$ & ar & $4-9$ & \\
\hline \multirow{2}{*}{$1 / T$} & \multirow{2}{*}{$\cdot M$} & $v 1 / r$ & $\Delta V$ & VN/A & $9 \pi$ & خانهدار & \multirow{2}{*}{ 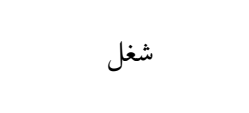 } \\
\hline & & YN/A & r & $r \mid r$ & IV & كارمند & \\
\hline \multirow{2}{*}{$\cdot / r Y$} & \multirow{2}{*}{$\cdot / r V$} & $49 / \pi$ & rv & $F Y / D$ & rF & آزاد & \multirow{2}{*}{ شغل همسر } \\
\hline & & $\Delta r / \Lambda$ & $\mathrm{kr}$ & $\Delta V / \Delta$ & 49 & كارمند & \\
\hline \multirow{5}{*}{$r / 4}$. & \multirow{5}{*}{$\cdot / 49$} & $V / \Delta$ & 9 & $9 / \pi$ & $\Delta$ & عالى & \multirow{5}{*}{ درآمد } \\
\hline & & $9 / r$ & $\Delta$ & $V / \Delta$ & 9 & خوب & \\
\hline & & $M r / \Delta$ & rq & $r r / \Delta$ & rq & متوسط & \\
\hline & & rN/A & m & $r V / \Delta$ & rr & بد & \\
\hline & & 10 & ir & $r q / r$ & r & خيلى بد & \\
\hline \multirow{4}{*}{$r / \Delta Q$} & \multirow{4}{*}{.194} & $r \mid / 9$ & 19 & $r / \Lambda$ & 19 & بع بو اد & \multirow{4}{*}{ سطح سو اد } \\
\hline & & $r Y / D$ & rF & ro & rA & 1 سال تحصيل & \\
\hline & & $\mathrm{rV} / \mathrm{\Delta}$ & 4. & rq/r & rq & rال تحصيل & \\
\hline & & $\Lambda / r$ & ir & $\Delta / 1$ & f & بيشتر از با سال & \\
\hline \multirow{3}{*}{$\Lambda / \Delta V$} & \multirow{3}{*}{$\cdot / \cdot v$} & $9 / \pi$ & $\Delta$ & $V / \Delta$ & 4 & عالى & \multirow{3}{*}{ ارزيابى سلامت دهان } \\
\hline & & $99 / \pi$ & $\Delta r$ & $\mathrm{FV} / \mathrm{q}$ & 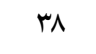 & خوب & \\
\hline & & $r V / 9$ & r & ra & rq & بد & \\
\hline \multirow{4}{*}{$\Delta / V \Lambda$} & \multirow{4}{*}{$\cdot / r \mid$} & $V I / r$ & FV & $91 / r$ & kq & دو سال يككبار & \multirow{4}{*}{ فر اوانى معاينات } \\
\hline & & $11 / r$ & $\wedge$ & $9 / \pi$ & $\Delta$ & سالى يككبار & \\
\hline & & 1. & 9 & $r$. & 19 & شش ماه يككبار & \\
\hline & & $\Lambda / \Lambda$ & 9 & $1 Y / \Delta$ & 1. & سه ماه يككبار & \\
\hline
\end{tabular}

جدول ؟: توزيع فراوانى مر احل تغيير رفتار تميز كردن دندان در دو كروه مداخله و كنترل بعد از آموزش

\begin{tabular}{|c|c|c|c|c|c|c|c|}
\hline جمع & نغكدارى & عمل & آمادگى & تفكر & بيش تفكر & \multirow{2}{*}{\multicolumn{2}{|c|}{ فراوانى }} \\
\hline$\Lambda$. & $r$. & $r F$ & $\Delta$ & 1. & 11 & & \\
\hline $1 \ldots$ & ro & $\mathrm{FY} / \mathrm{Q}$ & $9 / r$ & $1 Y / \Delta$ & $1 \% / \Lambda$ & درصد & \\
\hline$\wedge$. & $r$ & 9 & $\wedge$ & rr & rr & فراوانى & كنترل \\
\hline $1 \ldots$ & $9 / 1$ & $V / \Delta$ & 1. & f. & f. & درصد & \\
\hline
\end{tabular}


A。

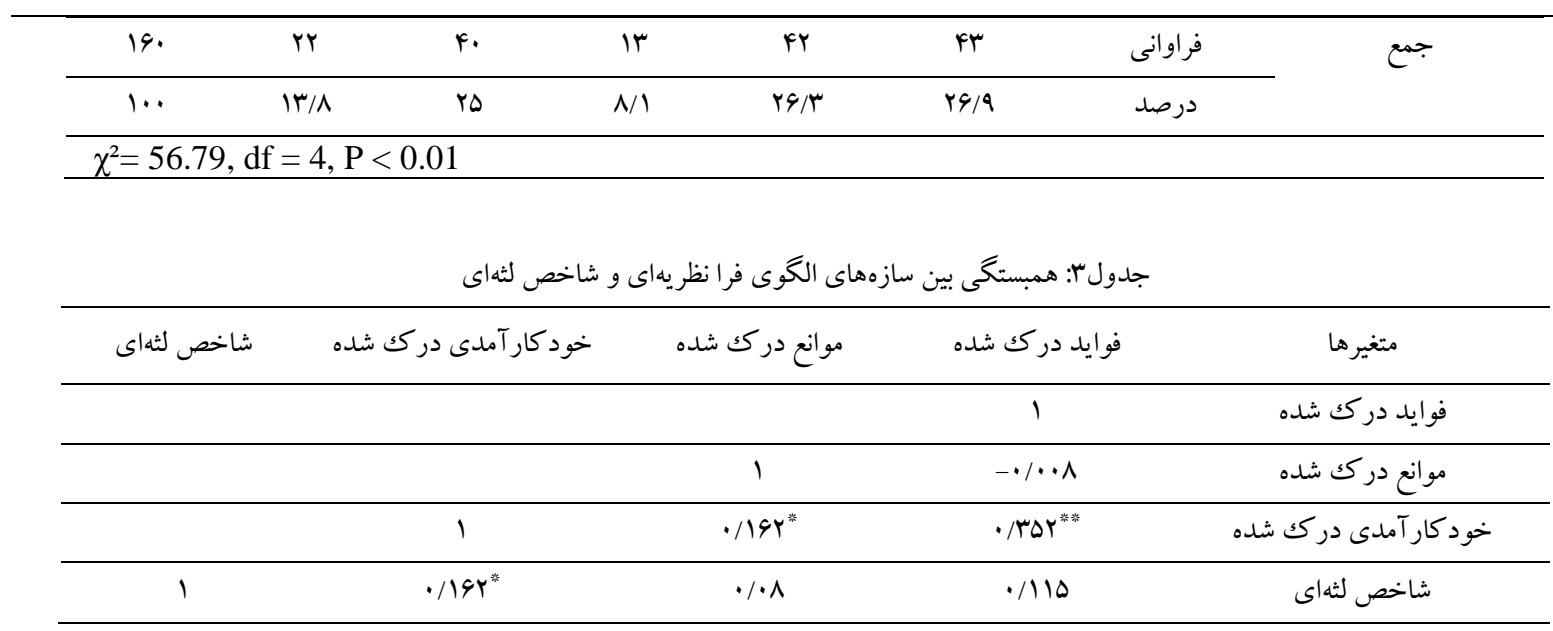

$* * \mathrm{p}<0.01$ (two-tailed)

$*$ p $<0.05$ (two-tailed)

\begin{tabular}{|c|c|c|c|c|}
\hline \multirow{2}{*}{ آزمون تى -مستقل } & \multicolumn{2}{|c|}{ بعد از مداخله } & \multirow{2}{*}{ كروه } & \multirow{2}{*}{ متغيرها } \\
\hline & انحر اف معيار & ميانگين & & \\
\hline \multirow{2}{*}{$\cdot / \cdot V$} & $F / V q$ & $r \Delta / \Lambda r$ & مداخله & \multirow{2}{*}{ خود كار آمدى دركى شده } \\
\hline & 9/Or & $Y F / Y I$ & كنترل & \\
\hline \multirow{2}{*}{$\cdot /$ TG } & $\Delta / \Delta G$ & YI/VG & مداخله & \multirow{2}{*}{ موانع دركك شده } \\
\hline & $\Delta / \Delta q$ & YY/VV & كنترل & \\
\hline \multirow{2}{*}{$\cdot 1 \cdot 1$} & $\Delta / \wedge \varphi$ & YF/A & مداخله & \multirow{2}{*}{ فوايد درك شده } \\
\hline & $\Lambda / Y)$ & $I V / V Y$ & كنترل & \\
\hline \multirow{2}{*}{$\cdot / \cdot r$} & $\cdot / \mathrm{AV}$ & $1 / 1$ & مداخله & \multirow{2}{*}{ شاخص لثهاى } \\
\hline & $\cdot / \mathrm{M}$ & $r / l$ & كنترل & \\
\hline
\end{tabular}

تصويرى، سخنرانى و جلسات حضورى جهت افزايش رفتار استفاده كردند احتمالاً اخر در اين مطالعات از روشهرئ آموزشى كه كسترده، يويا، جذاب و در دسترس بود استفاده بررسى حاضر اولين مطالعه مداخلهاى بود كه به ارائه مىشد ميزان انجام رفتار افزايش مىيافت. علت اينكه آموزشهاى مرتبط با سلامت دهان و دندان در زنان باردار از طريق شبكه اجتماعى تلكر ام برداخت. نتايج نشان داد كه اكثريت زنان در مطالعه ما رفتار را انجام دادند مىتوان به بعد از برنامه آموزشى تقريباً .V٪\% زنان باردار در گروه دلايلى ماند استفاده از كانال تلخرام، تجربه جديدى از آزمون، در مراحل انتهايى رفتار قرار داشته و از وسايل ارتباط و آموزش، دسترسى آسان و سريع به اطلاعات به تميزكننده دندان استفاده مى كردند كه اين تفاوت آمارى روز، محتواى آموزشى متنوع و جذاب، حمايت اجتماعى معنادارى با گروه كنترل داشت. در مطالعه Tavakoli و كافى (از نوع حمايت اطلاعاتى) و افزايش دركك از فوايد Fallahi رفتار اشاره داشت. كفتنى است از طريق شبكههاى اجتماعى و همكاران Hashemian آكاهى و دركك از سلامت و بيمارى افزايش مىيابد (YD) نكهدارى قرار داشته و رفتار تميز كردن دندان را انجام دادند كه اين با مبانى نظرى الكوى اعتقاد بهداشتى كه بيان مى كند

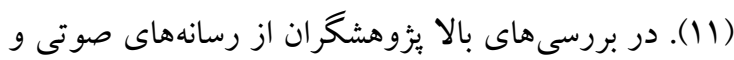


آنها، تمايل مادران به دريافت آموزش توسط متخصصان و عدم توجه آنها به آموزشهاى مراقبان سلامت مىتواند از دلايل بايين بودن دركك فوايد انجام رفتار در زنان باردار شر كت كننده در مطالعه باشد. نتايج مطالعه ما نشان داد كه برنامه آموزشى بر افزايش

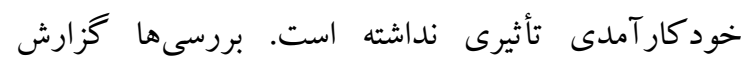
كردهاند كه كاهش ترس و اضطراب و افزايش توان و انكيزه، خودكار آمدى زنان باردار را جهت انجام رفتار افزايش مىدهد(سM ،YM). ديخر مطالعات نشان دادهاند خودكارآمدى مهممترين عامل در انجام رفتارهاى خود مراقبتى دهان و دندان بوده و افرادى كه رفتار را انجام مىدهند داراى خودكارآمدى بالاترى هستند (1) ، 11). احتمالاً عو املى همجون ارائه اطلاعات زياد در زمان كوتاه، عدم برگزارى جلسات و مشاورههاى انگگيزشى حضورى جهت انجام رفتار، بىتوجهى به ترس از انجام رفتار، عدم دريافت حمايت اجتماعى بلويثه حمايت عاطفى و ابزارى، شكست در انجام رفتار و عدم غلبه بر موانع از دلايل عدم افزايش معنادار خودكارآمدى دركك شده در زنان باردار بود. كميينهاى سلامت دهان و دندان در جهت افزايش

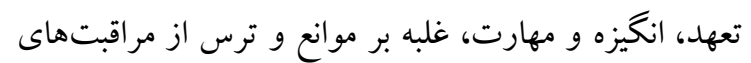
دندانيزشكى در دوران باردارى اساسى بوده، مىتواند انجام رفتار را بهبود بخشيده و توانايى و اطمينان زنان باردار را براى انجام ساير رفتارهاى بهداشتى بالا برد. شرايط دوران باردارى و تغيير زندگى آنان در اين دوران انجام رفتار رابا مشكل مواجهه مىسازد. بنابراين بهتر است اين كمبينها قبل از باردارى و حتى در سنين مدرسه انجام شود. كفتنى است آموزش رفتارهاى بيشخيرى كننده از دوران كودكى (MF) و انجام منظم مراقبتهاى دورهاى در مدارس بلهيزه مدارس دخترانه اهميت انجام اين رفتارها را يررنگك تر كرده و در بزرگكسالى آنان را با جالشهاى كمترى مواجهه مىسازد.
با افزايش درك از فوايد رفتار، انجام رفتار افزايش مىيابد در تطابق است (Y9). (Y) نتايج مطالعه ما نشان داد كه برنامه آموزشى بر افزايش فوايد دركك شده و كاهش التهاب لثه در زنان باردار مؤثر بوده است. در راستاى يافته هاى ما مطالعه Damle و همكاران نشان دادند كه برنامه آموزشى ارائه شده از طريق نمودارها و

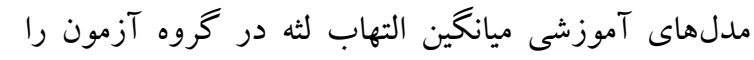
كاهش داد (YV). Tavakoli gallahi Tava بعد از برنامه آموزشى ارائه شده از طريق سخنرانى و نمايش عملى ميانگين فوايد و خود كار آمدى دركك شده افزايش و التهاب كاهش يافت (YN). Hashemian و همكاران كزارش كردند كه ميانگين نمرات خودكارآمدى، فوايد، موانع دركك شده و التهاب لثه بعد از برنامه مداخله در دو كرو آزمون و كنترل اختلاف آمارى معنادارى داشت( (1). زنان باردارى كه رفتارهاى مرتبط با سلامت دهان را انجام نمىدادند درك بإينى از فوايد دهان و دندان سالم داشتند. اين يافته همسو با ساير بررسى ها در زمينهى فوايد دركى شده

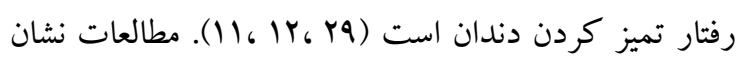
مىدهند كه مادران باردار خواستار افزايش درك فوايد سلامت دهان و دندان هستند. ادغام برنامههاى سلامت دهان و دندان در دروس مدارس، حمايتهاى اطلاعاتى از طريق مراقبان سلامت (·r)، خانواده، دوستان، فضاى مجازى و رسانهها از عوامل افزايش دركك فوايد رفتارهاى خود مراقبتى دهان و دندان در مادران باردار است (اسا). دركك فوايد رفتار و اثرات آن بر بدن مادر و فرزند يكى از بايههاى اساسى انجام رفتار منظم است. بدون اين دركك ييامدهاى ناكوارى مادر و فرزند را تهديد كرده و تلاش جهت رفع موانع انجام رفتار را مختل خواهد كرد. همسو با بررسى ما ساير مطالعات نيز نشان مىدهند افرادى كه دركك يايينى از فوايد رفتار دارند موانع بالاى رفتار را تجربه مى كنند (11). عدم توجه و حساسيت كافى مراقبان سلامت بهسلامت دهان و دندان مادران باردار و ارائه آموزشهاى ضعيف توسط 


$$
\begin{aligned}
& \text { يُروهشهاى آينده بيشنهاد مىشود. نتايج اين مطالعه مى تواند } \\
& \text { علىرغم محدوديتهاى مانند ابزار خود گزّارشى، عدم } \\
& \text { براى دندانيز شكان، متخصصان سلامت، متخصصان زنان و } \\
& \text { ييخيرى نتايج در بلندمدت و عدم حضور ساير زنان در } \\
& \text { مراقبان سلامت جهت طراحى برنامههاى آموزشى به منظور } \\
& \text { ارتقا سلامت دهان و دندان مفيد باشد. }
\end{aligned}
$$

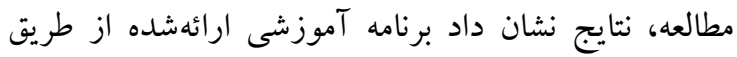

$$
\begin{aligned}
& \text { شبكه اجتماعى تلكرام بر كاهش التهاب لثه در زنان باردار }
\end{aligned}
$$

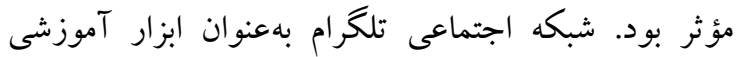

$$
\begin{aligned}
& \text { تشكر و قدردانى } \\
& \text { الكترونيكى مىتو اند در آموزش هاى مر تبط به سلامت دهان } \\
& \text { اين مقاله برگرفته از طرح تحقيقاتى مصوب معان معاونت } \\
& \text { و دندان مفيد بوده و وضعيت مبتلايان به بيمارىهاى دهان را }
\end{aligned}
$$

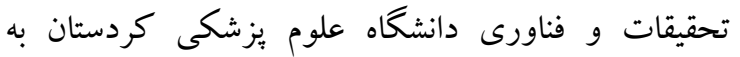

$$
\begin{aligned}
& \text { شماره IR.MUK.REC.1395.321 است. لذا محققين } \\
& \text { بر خود لازم مىداند از معاونت يُزوهشى دانشكاه كه } \\
& \text { هزينههاى اجراى طرح را بر عهده داشته و از كليه مادران }
\end{aligned}
$$

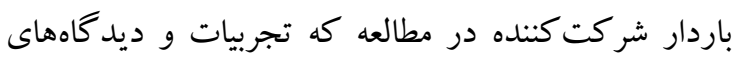

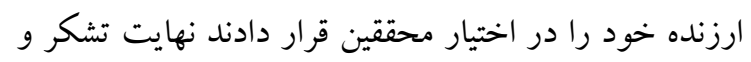

$$
\begin{aligned}
& \text { قدردانى را ابراز نمايند. }
\end{aligned}
$$

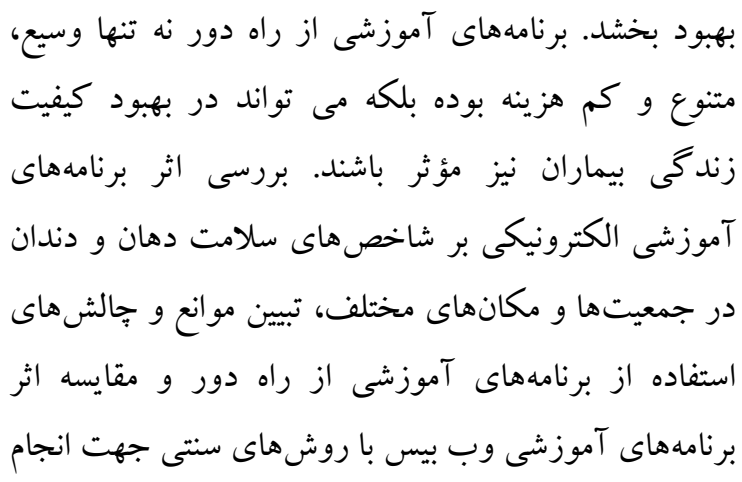

\section{References}

1. Bahri N, Iliati H, Bahri N, Sajjadi M, Boloochi T. Effects of oral and dental health education program on knowledge, attitude and short-time practice of pregnant women (Mashhad-Iran). J Mash Dent Sch 2012;36:1-12. [In Persian]

2. Shamsi M, Hidarnia A, Niknami S, Atarha M, Jadidi R. Oral health of pregnant women in Arak, Iran. Payesh Journal 2013;12:355-65.

3. Ryalat S, Sawair F, Baqain Z, Barghout N, Amin W, Badran D, et al. Effect of oral diseases on mothers giving birth to preterm infants. Med Princ Pract 2011;20:556-61.

4. Laine M. Effect of pregnancy on periodontal and dental health. Acta Odontol Scand. 2002;60:25764.

5. Thomas N, Middleton P, Crowther C. Oral and dental health care practices in pregnant women in Australia: A postnatal survey. BMC Pregnancy Childbirth 2008;21:13.

6. Strafford K, Shellhaas C, Hade E. Provider and patient perceptions about dental care during pregnancy. J Matern Fetal Neonatal Med 2008;21:63-71.

7. Soroye M, Ayanbadejo P. Prevalence of gingivitis and perception of gingival colour among pregnant women attending the antenatal clinic of Lagos University Teaching Hospital, Irabdi-Aa. J Orofac Sci 2016;8:53-8.

8. Mital P, Amit P, Raisingani D, Mital P, Hooja N, Priyanka N. Dental caries and gingivitis in pregnant women. Sch J App Med Sci 2013;16:718-23.

9. Saddki N, Yusoff A, Hwang Y. Factors associated with dental visit and barriers to utilisation of oral health care services in a sample of antenatal mothers in Hospital Universiti Sains Malaysia. BMC Public Health 2010;10:75.

10. Hashemian M, Fallahi A, Gharibi F, Fallahi P. Explaining process of dental caries from women's viewpoint: study with grounded theory approach. SJSPH 2014;11:65-84. [In Persian]

11. Hashemian M, Fallahi A, Tavakoli G, Zarezadeh Y, Nemat Shahr Babaki B, Rahaei Z. Study of the Impact of Education on Inter-Dental Cleaning behavior based onTrans-Theoretical Model. Oral Health Prev Dent2012;1:37-46. 
12. Shamsi M, Hidarnia A, Niknami S. Self-Reported Oral Hygiene Habits and Self-Care in the Oral Health in Sample of Iranian Women During Pregnancy. World Appl Sci J 2013;22: 647-56.

13. Solhi M, Shojaee Zadeh D, Seraj B, Faghih Z. Application of HBM in oral health education. Toloo-e- Behdasht 2003;2:99. [In Persian]

14. Mahdiye Rezaei M, Shobeiri S, Sarmadi M, Larijani M. The effect of instagram social network usage on the Promotion of environmental Literacy of students. J Environ Sci 2016;14:89-106.

15. Balappanavar A, Sardana V, Hegde P. Social Networking and Oral Health Education. Int J Sci Study 2013;10:16-9.

16. Bull S, Breslin L, Wright E, Black S, Levine D, Santelli J. Case study: an ethics case study of hiv prevention research on facebook: the just/us study. J Pediatr Psychol 2011;36:1082-92.

17. Taymoori P, Fallahi A, Berry T. Development and testing of the decision balance and self efficacy for oral self-care among Iranian adolescents. Eastern J Med 2011;16:261-8.

18. Morowatisharifabad M, Fallahi A, Nadrian H, Haerian A, Neamatshahrbabaki B. Inter-dental cleaning behavior and its relationship with psychological constructs based on the Transtheoretical model. Oral Health Prev Dent 2011;9:211-20.

19. Fallahi A, Ghofranipour F, Ahmadi F, Malekafzali B, Hajizadeh E. Challenges of Iranian adolescents for preventing of dental caries. Iran Red Crescent Med J 2014;16:1-7.

20. Christensen P. The health-promoting family: a conceptual framework for future research. Soc Sci Med 2004;59:377-87.

21. Tilliss T, Stach D, Cross-Poline G, Annan S, Astroth D, Wolfe P. The Transtheoretical model applied to an oral self-care behavioral change: development and testing of instruments for stages of change and decisional balance. J Dent Hyg 2003;77:16-25.

22. Bandura A. Self-efficacy: toward a unifying theory of behavioral change. Psychol Rev1977;84:191-215.

23. Bhardwaj V, Sharma K, Luthra R, Jhingta P, Sharma D, Justa A, et al. Impact of school-based oral health education program on oral health of 12 and 15 years old school children. J Edu Health Promot 2013;2:33.

24. Tavakoli G, Fallahi A. The effect of educating mothers in inter-dental cleaning behavior on their children's dental health behavior: testing the transtheoretical model. HEHP 2013;1:5-19.

25. Chou W, Hunt Y, Beckjord E, Moser R, Hesse B. Social media use in the United States: implications for health communication. J Med Internet Res 2009;11(4):48.

26. Solhi M, Shojaei Zadeh D, Seraj B, Faghih Zadeh S. The application of the health belief model in oral health education. Iran J Public Health 2010;39:114-9.

27. Damle S, Patil A, Jain S, Damle D, Chopal N. Effectiveness of supervised toothbrushing and oral health education in improving oral hygiene status and practices of urban and rural school children: A comparative study. J Int Soc Prev Community Dent 2014;4:175-81.

28. Tavakoli G, Fallahi A. The effect of educating mothers in inter-dental cleaning behavior on their children's dental health behavior: testing the transtheoretical model. HEHP 2013;1:5-19.

29. Watt RG. Emerging theories into the social determinants of health: implications for oral health promotion. Community Dent Oral Epidemiol 2002; 30: 241-7.

30. George A, Johnson M, Duff M, Blinkhorn A, Ajwani S, Bhole S, et al. Maintaining oral health during pregnancy: perceptions of midwives in Southwest Sydney. Collegian 2011;18:71-9.

31. George A, Johnson M, Duff M, Ajwani S, Bhole S, Blinkhorn A, et al. Midwives and oral health care during pregnancy: perceptions of pregnant women in south-western Sydney, Australia. J Clin Nurs 2012:1087-96.

32. Shenoy R, Chacko V. Utilization of dental services due to dental pain by pregnant women in India: A qualitative analysis. J Interdiscip Dentistry 2013;3:18-20.

33. Buerlein J, Horowitz A, W C. Perspectives of Maryland women regarding oral health during pregnancy andearly childhood. J Public Health Dent 2011;71:131-5. 
34. Fallahi A, Nemat Shahrbabaki B, Hashemian M, Asadolahe Ahmadi Kahanali A. The needs of women referring to health care centers for doing Pap smear Test. IJOGI 2016;19:1-10. [In Persian] 